\title{
PROGRAMMABLE CURRENT-MODE UNIVERSAL ACTIVE FILTERS EMPLOYING CURRENT CONVEYORS
}

\author{
MUHAMMAD TAHER ABUELMA'ATTI \\ King Fahd University of Petroleum and Minerals, Box 203, \\ Dhahran 31261, Saudi Arabia
}

(Received 1 February 1998; In final form 15 April 1998)

\begin{abstract}
Novel current-mode active filter circuits using current-conveyors are presented. The proposed circuits can realize all standard second-order filter functions. The circuits enjoy high output impedances and can, therefore, be easily cascaded to produce higher order filters. Moreover, the realized filter function can be easily programmed using at most a 13-bit digital number without changing the circuit topology.
\end{abstract}

Keywords: Active filters; current conveyors

\section{INTRODUCTION}

At present there is a growing interest in designing analog current-mode signal processing circuits. In these circuits the current, rather than the voltage, is used as the active variable either throughout the whole circuit or only in certain critical areas [1]. The use of current as the active parameter can result in circuits operating with higher bandwidths, greater linearity and larger dynamic range than voltagemode circuits $[1,2]$. The current conveyor; a powerful analog building block with a current-mode capability, is therefore a highly potential candidate for implementation of current-mode circuits, and recently a number of realizations has been presented using the first-generation (CCI) and the second-generation (CCII) current-conveyors [3-31].

Despite the fact that many current-conveyor-based universal filters, which implement the lowpass (LP), highpass (HP), bandpass (BP), 
bandreject (BR) and allpass (AP) second-order transfer functions, have been presented, no attempt has been reported for investigating the feasibility of programming the filter function. Many applications require filter programmability. For example in analog signal processing the need may arise for the adaptive programming of the filter function.

The major intention of this paper is, therefore, to present two circuit configurations for realizing current-conveyor-based filters with programmable functions. Each circuit uses a single current-conveyor and a number of resistors, capacitors and digitally-controlled switches. Using a 13-bit digital number, both circuits can be configured to provide any of the five basic filter functions.

\section{PROPOSED NETWORKS}

\subsection{First Configuration}

Consider the circuit shown in Figure 1(a). Assuming ideal current conveyors with $i_{x}=i_{y}=i_{z}, v_{x}=v_{y}$ for the CCI and $i_{x}=i_{z}, i_{y}=0$, $v_{x}=v_{y}$ for the CCII, routine analysis yields

$$
\begin{aligned}
& F=\frac{i_{o}}{i_{i}}=\frac{-1}{1+\frac{z_{1}}{z_{2}}+\frac{z_{1}}{z_{3}}+\frac{z_{1} z_{4}}{z_{2} z_{3}}-\frac{z_{4}}{z_{2}}} \\
& G=\frac{i_{1}}{i_{i}}=\frac{-\left(\frac{z_{1}}{z_{3}}-1\right)}{1+\frac{z_{1}}{z_{2}}+\frac{z_{1}}{z_{3}}+\frac{z_{1} z_{4}}{z_{2} z_{3}}-\frac{z_{4}}{z_{2}}}
\end{aligned}
$$

when the CCI is used, and

$$
\begin{gathered}
H=\frac{i_{o}}{i_{i}}=\frac{-1}{1+\frac{z_{1}}{z_{2}}+\frac{z_{1}}{z_{3}}+\frac{z_{1} z_{4}}{z_{2} z_{3}}} \\
K=\frac{i_{1}}{i_{i}}=\frac{-\frac{z_{1}}{z_{3}}}{1+\frac{z_{1}}{z_{2}}+\frac{z_{1}}{z_{3}}+\frac{z_{1} z_{4}}{z_{2} z_{3}}}
\end{gathered}
$$

when the CCII is used. 

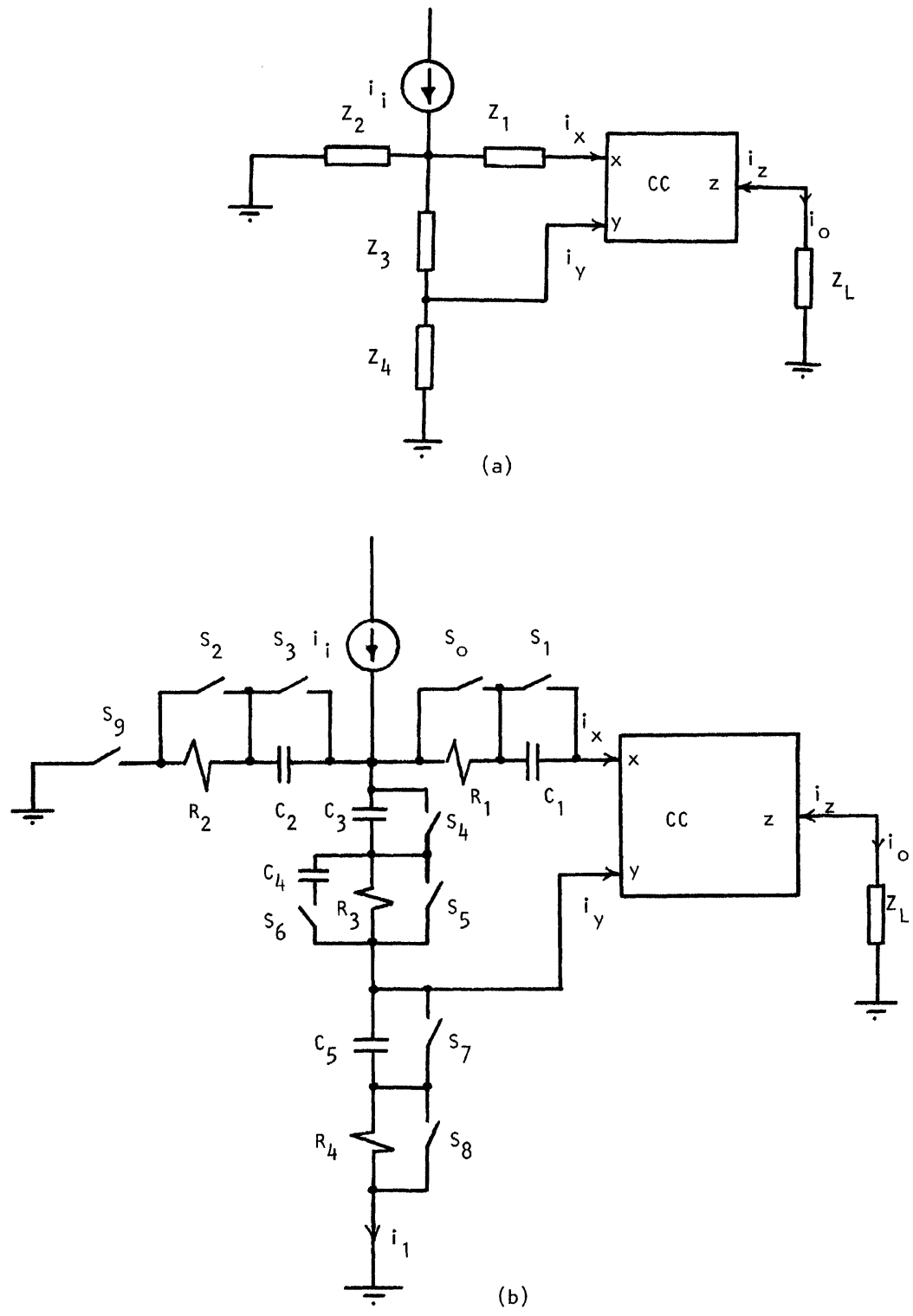

FIGURE 1 First Configuration. 
The current $i_{o}=-i_{z}$ is directly obtained through the $z$-port of the current-conveyor and the current $i_{1}$ is obtained through another current conveyor which must exhibit a virtual ground on input. Using Eqs. (1) -(4) all the standard biquads can be realized. Figure $1(\mathrm{~b})$ shows a possible realization of the impedances $Z_{1}-Z_{4}$ and Table I shows the various characteristics of current transfer-functions (TF) which can be obtained by varying the nature of the impedances $Z_{1}-Z_{4}$ using the switches $S_{0}-S_{9}$. From Table I it is easy to see that the current transferfunction (TF) can be programmed by changing the digital number applied to switches $S_{0}-S_{9}$. From Table I it can also be seen that it is possible to adjust parameter $\omega_{o}$ for cases $1-6$ without disturbing the parameter $\omega_{o} / Q_{o}$. However, the parameter $\omega_{o} / Q_{o}$ cannot be adjusted without disturbing the parameter $\omega_{o}$. Thus, these realizations enjoy orthogonal tuning of the parameters $\omega_{o}$ and $\omega_{o} / Q_{o}$.

\subsection{Second Configuration}

Consider the circuit shown in Figure 2(a). Assuming ideal current conveyor, routine analysis yields

$$
\begin{aligned}
& A=\frac{i_{o}}{i_{i}}=\frac{-1}{1+\frac{z_{2}}{z_{1}}+\left(1+\frac{z_{2}}{z_{1}}+\frac{z_{3}}{z_{1}}\right)\left(\frac{z_{4}-z_{5}}{z_{3}}\right)} \\
& B=\frac{i_{1}}{i_{i}}=\frac{-\left(\frac{z_{4}-z_{5}}{z_{3}}\right)}{1+\frac{z_{2}}{z_{1}}+\left(1+\frac{z_{2}}{z_{1}}+\frac{z_{3}}{z_{1}}\right)\left(\frac{z_{4}-z_{5}}{z_{3}}\right)}
\end{aligned}
$$

when the CCI is used, and

$$
\begin{aligned}
& M=\frac{i_{o}}{i_{i}}=\frac{-1}{1+\frac{z_{2}}{z_{1}}+\left(1+\frac{z_{2}}{z_{1}}+\frac{z_{3}}{z_{1}}\right) \frac{z_{4}}{z_{3}}} \\
& N=\frac{i_{1}}{i_{i}}=\frac{-\frac{z_{4}}{z_{3}}}{1+\frac{z_{2}}{z_{1}}+\left(1+\frac{z_{2}}{z_{1}}+\frac{z_{3}}{z_{1}}\right) \frac{z_{4}}{z_{3}}}
\end{aligned}
$$

when the CCII is used. 


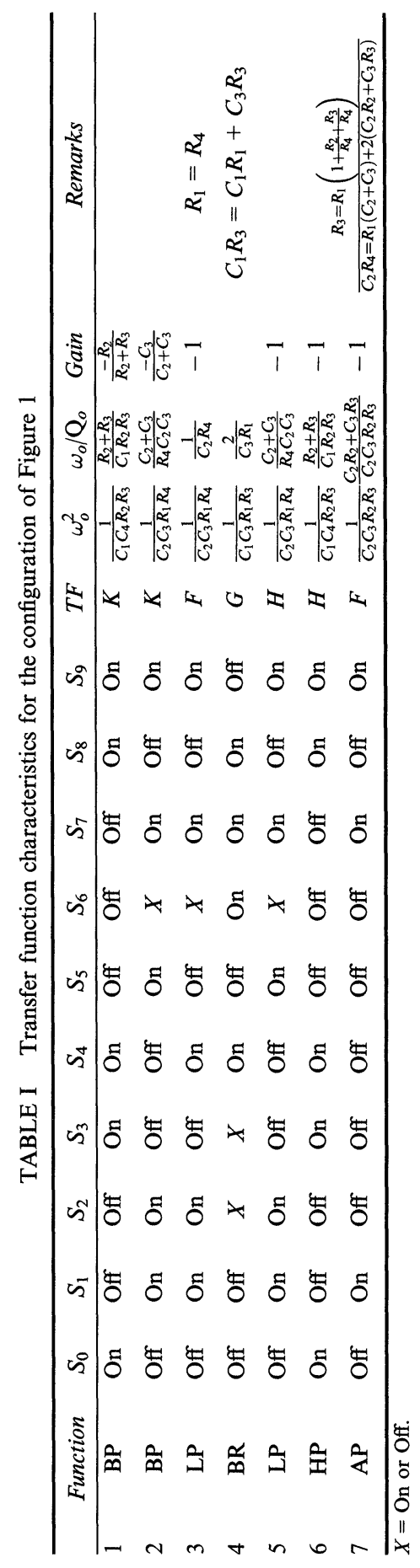




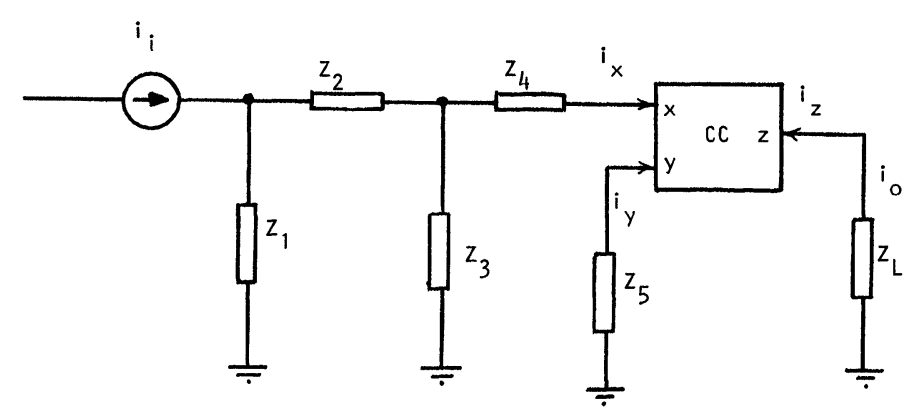

(a)

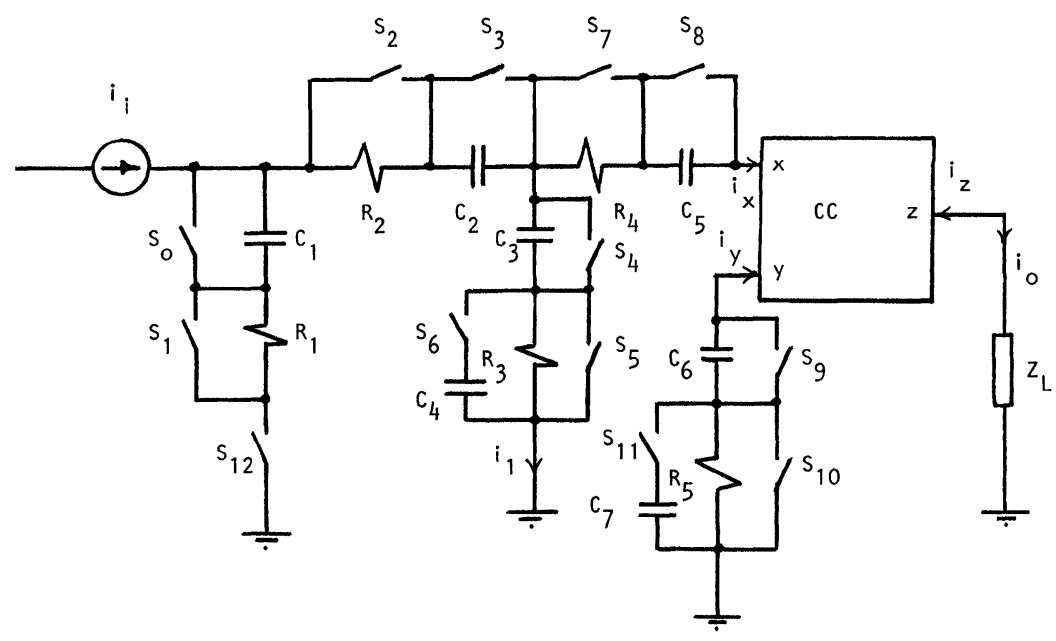

(b)

FIGURE 2 Second Configuration.

Using Eqs. (5) - (8) all the standard biquads can be realized. Figure 2(b) shows a possible realization of the impedances $Z_{1}-Z_{5}$ and Table II shows the various characteristics of current transfer-functions (TF) which can be obtained by varying the nature of the impedances $Z_{1}-Z_{5}$ using the switches $S_{0}-S_{12}$. From Table II it is easy to see that the current transfer-function (TF) can be programmed by changing the digital number applied to switches $S_{0}-S_{12}$. From Table II it can also be seen that it is possible to adjust parameter $\omega_{o}$ for case 1 without 


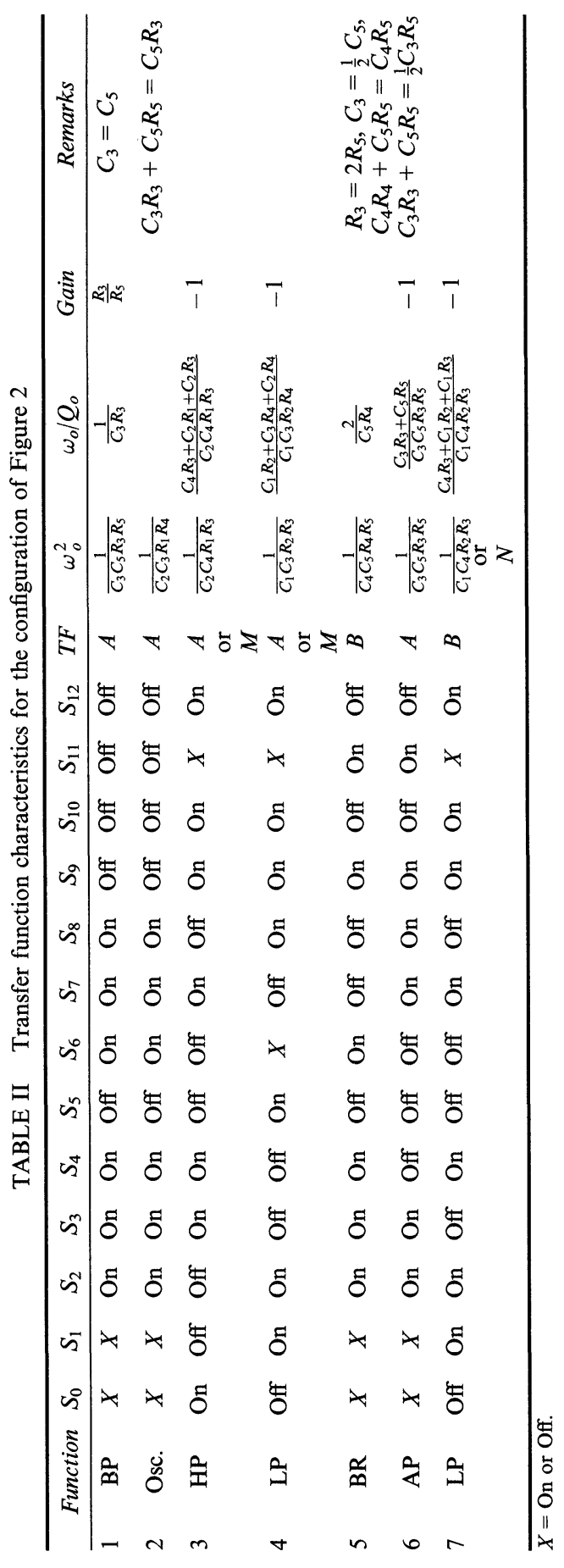


disturbing the parameter $\omega_{o} / Q_{o}$. However, the parameter $\omega_{o} / Q_{o}$ cannot be adjusted without disturbing the parameter $\omega_{o}$. Thus, this realization enjoys orthogonal tuning of the parameters $\omega_{o}$ and $\omega_{o} / Q_{o}$.

Finally, Table II shows that a sinusoidal oscillator can be realized in case 2.

\section{FIRST-ORDER FILTER SECTIONS}

First-order highpass and lowpass filter actions can be obtained from the circuit of Figure 1(a) by setting $Z_{2}=\infty$, thus Eqs. (3) and (4) reduce to

$$
H=\frac{i_{0}}{i_{i}}=\frac{-Z_{3}}{Z_{1}+Z_{3}}
$$

and

$$
K=\frac{i_{1}}{i_{i}}=\frac{-Z_{1}}{Z_{1}+Z_{3}}
$$

respectively. Therefore, by choosing $Z_{1}=R_{1}$ and $Z_{3}=1 / s C_{3}$, Eqs. (9) and $(10)$ reduce to

$$
H(s)=\frac{I_{0}}{I_{i}}=\frac{-1}{1+s C_{3} R_{1}}
$$

and

$$
K(s)=\frac{I_{1}}{I_{i}}=\frac{-s C_{3} R_{1}}{1+s C_{3} R_{1}}
$$

respectively. Equation (11) corresponds to the current transferfunction (TF) of the first-order LPF and Eq. (12) corresponds to the transfer function of a first-order HPF. Similar results can be obtained by setting $Z_{1}=\infty$ in Figure 2(a).

\section{DISCUSSION AND CONCLUSION}

From Tables I and II it is obvious that all the standard biquads can be obtained from the configurations of Figures (1) and (2) by closing or 
opening the appropriate switches using, at most, a 13-bit digital word. The first order highpass and lowpass filter sections, can also be obtained.

By defining the sensitivity of a parameter $F$ to the element of variation $x_{i}$ by

$$
S_{x_{i}}^{F}=\frac{x_{i}}{F} \frac{d F}{d x_{i}}
$$

it is easy to show that the sensitivity of the parameters $\omega_{o}$ and $\omega_{o} / Q_{o}$ are less than unity. Thus the proposed configurations enjoy low sensitivities.

By using CMOS-SPST switches and if the control voltges of these switches are obtained from the output port of a microprocessor, then the implementation of a microprocessor-controlled universal currentmode filter networks is feasible.

\section{References}

[1] Wilson, B. (1990). Recent developments in current conveyors and current-mode circuits, IEE Proceedings, 137, Pt. G, 63-70.

[2] Roberts, G. W. and Sedra, A. S. (1989). All current-mode frequency selective circuits, Electronics Letters, 29, 759-761.

[3] Aronhime, P., Nelson, D. and Adams, C. (1990). Applications of a first-generation currrent conveyor in current-mode circuits, Electronics Letters, 26, 1456-1457.

[4] Fabre, A., Martin, F. and Hanafi, M. (1990). Current mode allpass/notch and bandpass filters with reduced sensitivities, Electronics Letters, 26, 1495-1496.

[5] Higashimura, M. and Fukui, Y. (1990). Realization of current mode all-pass networks using a current conveyor, IEEE Transactions in Circuits and Systems, 37, $660-661$

[6] Liu, S.-I., Tsao, H.-W. and Wu, J. (1990). Cascadable current-mode single CCII, Electronics Letters, 26, 2005-2006.

[7] Chang, C.-M. and Chen, P. -C. (1991). Universal active current filter with three inputs and one output using current conveyors, International Journal of Electronics, 71, 817-819.

[8] Chang, C.-M. and Chen, P.-C. (1991). Realization of current-mode transfer function using second-generation current conveyors, International Journal of Electronics, 71, 809-815.

[9] Chang, C.-M. (1991). Universal active current filters using single second-generation current conveyor, Electronics Letters, 27, 1614-1617.

[10] Hou, C.-L., Wu, Y. -P. and Liu, S.-I. (1991). New configuration for single-CCII first-order and biquadratic current-mode filters, International Journal of Electronics, 71, 637-644.

[11] Aronhime, P. and Dinwiddie, A. (1991). Biquadratic current-mode filters using a single CCI, International Journal of Electronics, 70, 1063-1071.

[12] Chang, C.-M. (1991). Current mode allpass/notch and bandpass filter using CCII, Electronics Letters, 27, 1812-1813. 
[13] Senani, R. (1992). New current-mode biquad filter, International Journal of Electronics, 73, 735-742.

[14] Chang, C.-M., Chien, C.-C. and Wang, H.-Y. (1993). Universal active current filters using single second-generation current conveyor, Electronics Letters, 29, $1159-1160$.

[15] Abuelma'atti, M. T. (1993). New current-mode-active filters employing current conveyors, International Journal of Circuit Theory and Applications, 21, 93-99.

[16] Wu, D.-S., Hwang, Y.-S., Liu, S. I. and Wu, Y.-P. (1994). New multifunction filter using an inverting CCII and a voltage follower, Electronics Letters, 30, 551-552.

[17] Sun, Y. and Fidler, J. K. (1994). Versatile active biquad based on secondgeneration current conveyors, International Journal of Electronics, 76, 91-98.

[18] Chang, C.-M. (1993). Current-mode lowpass, bandpass and highpass biquads using two CCIIs, Electronics Letters, 29, 2020-2021.

[19] Chang, C.-M. (1993). Novel universal current-mode filter with single input and three outputs using only five current conveyors, Electonics Letters, 29, 2005-2007.

[20] Chang, C.-M. (1993). Universal active current filter with single input and three outputs using CCIIs, Electronics Letters, 29, 1932-1933.

[21] Soliman, A. M. (1995). Current mode universal filter, Electronics Letters, 31, $1420-1421$

[22] Abuelma'atti, M. T. and Shabra, A. M. (1996). A novel current-conveyor-based universal current-mode filter, Microelectronics Journal, 27, 471-475.

[23] Gunes, E. O. and Anday, F. (1996). Realisation of current-mode universal filter using $\mathrm{CFCCII}_{\mathrm{p}} \mathrm{s}$, Electronics Letters, 32, 1081-1082.

[24] Senani, R. (1996). A simple approach of deriving single-input-multiple-output current-mode biquad filters, FREQUENZ, 50, 124-127.

[25] Karyabakas, C. A. and Papazoglou, C. A. (1996). Current-mode CCII-based biquadratic filters offering electronic frequency shifting, International Conference on Electronics, Circuits and Systems, Greece, pp. 128-131.

[26] Acar, C. (1997). On the realization of current-mode filters using second-generation current conveyors, International Journal of Circuit Theory and Applications, 25, $229-233$.

[27] Chang, C.-M. (1997). Universal active current filter with three inputs and one using plus-type CCIIs, Electronics Letters, 33, 1207-1208.

[28] Lata, Z. J. and Aronhime, P. B. (1997). Cascadable current-mode biquads, Analog Integrated Circuits and Signal Processing, 13, 275-284.

[29] Papazoglou, C. A. and Karybakas, C. A. (1997). Noninteracting electronically tunable CCII-based current-mode biquadratic filters, IEE Proceedings-Circuits Devices Systems, 144, 178-184.

[30] Hou, C.-L. and Wu, J.-S. (1997). Universal cascadable current-mode biquad using only four CCIIs, International Journal of Electronics, 82, 125-129.

[31] Abuelma'atti, M. T., Current mode active filters which current conveyors, Electronic Engineering, 66, July 1994, pp. 48-49. 

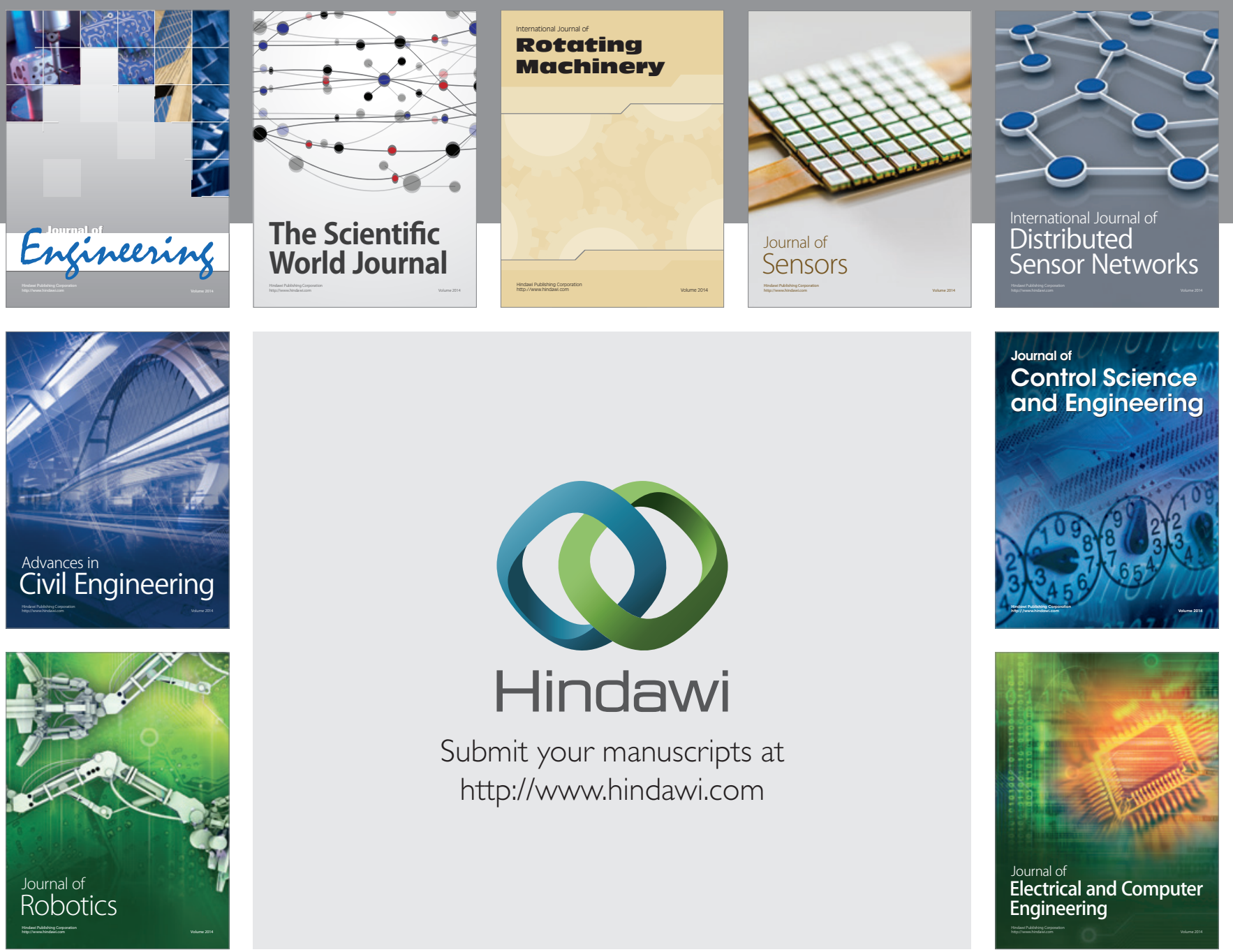

Submit your manuscripts at

http://www.hindawi.com
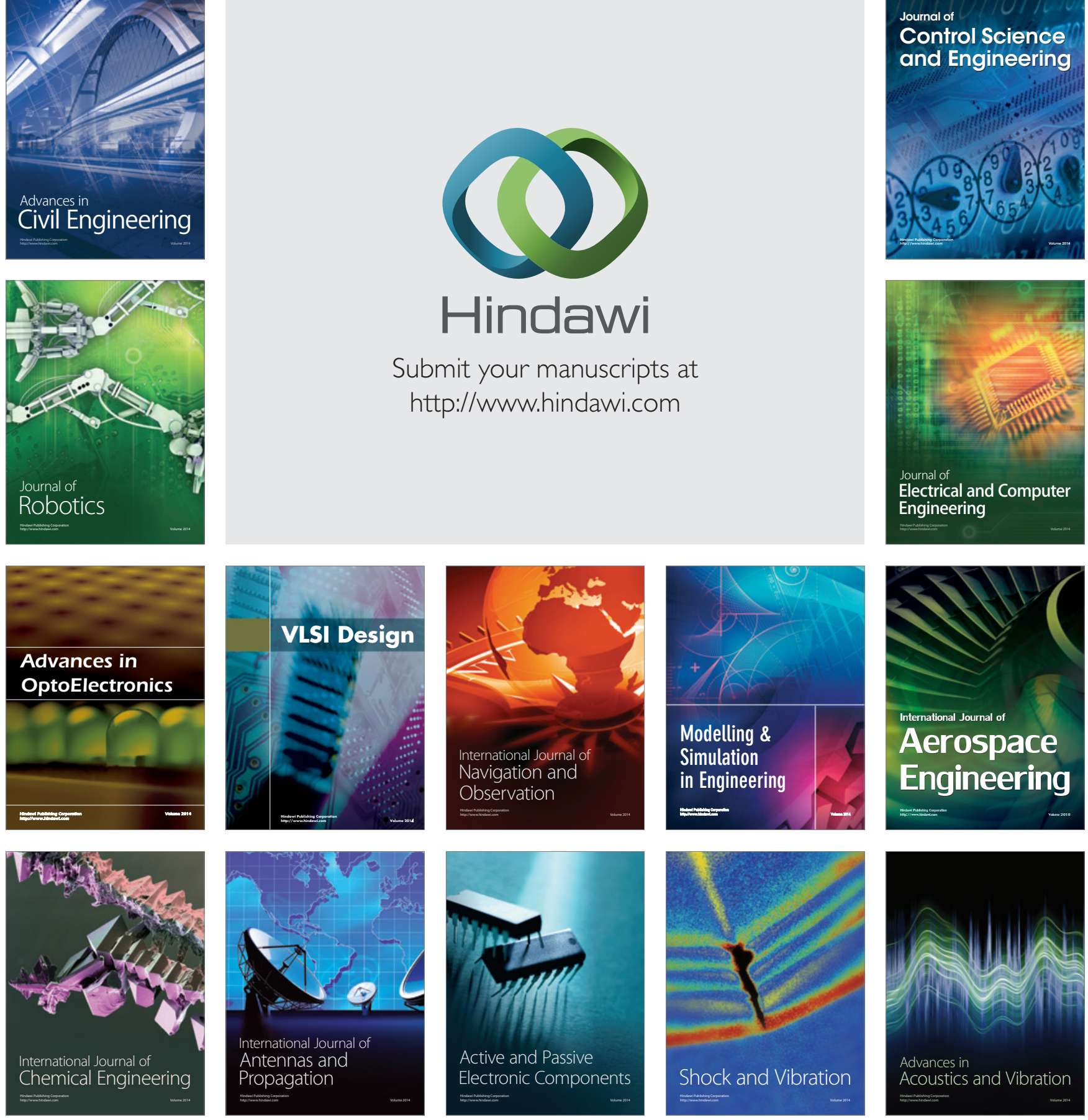